\title{
Ethnic inequalities in the incidence of diagnosis of severe mental illness in England: a systematic review and new meta-analyses for non-affective and affective psychoses
}

\author{
Kristoffer Halvorsrud ${ }^{1}$. James Nazroo ${ }^{2} \cdot$ Michaela Otis $^{1} \cdot$ Eva Brown Hajdukova $^{3} \cdot$ Kamaldeep Bhui $^{1}$
}

Received: 16 March 2019 / Accepted: 20 August 2019 / Published online: 3 September 2019

(c) The Author(s) 2019

\begin{abstract}
Purpose Although excess risks particularly for a diagnosis of schizophrenia have been identified for ethnic minority people in England and other contexts, we sought to identify and synthesise up-to-date evidence (2018) for affective in addition to non-affective psychoses by specific ethnic groups in England.

Methods Systematic review and meta-analysis of ethnic differences in diagnosed incidence of psychoses in England, searching nine databases for reviews (citing relevant studies up to 2009) and an updated search in three databases for studies between 2010 and 2018. Studies from both searches were combined in meta-analyses allowing coverage of more specific ethnic groups than previously.

Results We included 28 primary studies. Relative to the majority population, significantly higher risks of diagnosed schizophrenia were found in Black African (Relative risk, RR 5.72, 95\% CI 3.87-8.46, $n=9$ ); Black Caribbean (RR 5.20, 95\% CI 4.33-6.24, $n=21$ ); South Asian (RR 2.27, 95\% CI 1.63-3.16, $n=14$ ); White Other (RR 2.24, 95\% CI 1.59-3.14, $n=9$ ); and Mixed Ethnicity people (RR 2.24, 95\% CI 1.32-3.80, $n=4$ ). Significantly higher risks for diagnosed affective psychoses were also revealed: Black African (RR 4.07, 95\% CI 2.27-7.28, $n=5$ ); Black Caribbean (RR 2.91, 95\% CI 1.78-4.74, $n=16$ ); South Asian (RR 1.71, 95\% CI 1.07-2.72, $n=8$ ); White Other (RR 1.55, 95\% CI 1.32-1.83, $n=5$ ); Mixed Ethnicity (RR 6.16, 95\% CI 3.99-9.52, $n=4$ ).

Conclusions The risk for a diagnosis of non-affective and affective psychoses is particularly elevated for Black ethnic groups, but is higher for all ethnic minority groups including those previously not assessed through meta-analyses (White Other, Mixed Ethnicity). This calls for further research on broader disadvantages affecting ethnic minority people.
\end{abstract}

Keywords Schizophrenia $\cdot$ Affective psychoses $\cdot$ Incidence $\cdot$ Ethnicity $\cdot$ Meta-analysis

\section{Introduction}

Electronic supplementary material The online version of this article (https://doi.org/10.1007/s00127-019-01758-y) contains supplementary material, which is available to authorized users.

Kamaldeep Bhui

k.s.bhui@qmul.ac.uk

1 Centre for Psychiatry, Wolfson Institute of Preventive Medicine, Barts and the London School of Medicine and Dentistry, Queen Mary University of London, Charterhouse Square, London EC1M 6BQ, UK

2 Sociology, School of Social Sciences, University of Manchester, Humanities, Bridgeford Street, Oxford Road, Manchester M13 9PL, UK

3 Centre for Research in Public Health \& Community Care (CRIPACC), University of Hertfordshire, Health Research Building, College Lane, Hatfield AL10 9AB, UK
Elevated risks in the incidence of diagnosis of psychoses, specifically schizophrenia, have been shown for migrant and ethnic minority groups across four different continents [1-5], over many decades [1, 5-7], in both first and second generation migrants $[8,9]$ and adjusted for age and gender $[5,10,11]$. Alongside a family history $[8,12]$ and living in larger urban areas or with greater levels of urbanicity [11,13], high risks of diagnosis of psychotic disorders are most consistently associated with ethnic minority or migrant status than other demographic characteristics $[8,11]$. The over-representation of ethnic minority people receiving diagnoses at the severe end is particularly concerning [14], with the schizophrenia incidence for Black Caribbean people in the UK identified 
as amongst the highest in the world [9, 11, 15] and not replicated in 'native' populations in Caribbean contexts [16-18].

Previous meta-analyses have tended to aggregate data from a diversity of settings and ethnic groups [8, 9, 19-23] combining ethnic minority people regardless of diverse identities and pre- and post-migrant experiences [19, 22, 23]—against a 'native' reference population. Although some reviewers have synthesised and reported summary estimates for studies conducted in the UK [9] or England more specifically [11, 15], data for some ethnic groups has not been pooled largely due to the limited evidence base (i.e. for people of Mixed Ethnicity, White Other). In addition, the incidence of diagnosis of affective psychoses is not as well understood. Some reports indicate excess diagnosis risks in both types of psychoses for ethnic minority or migrant groups [24-27], while other reports have demonstrated that the diagnosis of non-affective psychoses, or schizophrenia specifically, is particularly raised $[11,23]$, or that the diagnosis of affective psychoses may not be significantly higher for certain ethnic minority compared to the reference populations [20, 22].

We sought to expand on the literature by providing a detailed synthesis of the up-to-date evidence (until the end of 2018) on ethnic inequalities in the diagnosed incidence of affective and non-affective psychoses as they relate specifically to England, asking the following questions:

1. Are specific ethnic groups at a particularly elevated risk of receiving a diagnosis of psychoses?

2. Are findings consistent across non-affective and affective psychoses?

3. Are findings consistent through time?

4. What other sources of heterogeneity may explain ethnic variations in risks?

Our investigations of heterogeneity were influenced by previous meta-analyses that have hypothesised potentially important and variously examined variables that may moderate or mediate the effects of ethnicity on the diagnosed incidence of psychoses. In accordance with previous metaanalyses, we focused on time [15], nationality [11], gender $[8,9,11,19,20,22]$, age $[11,22]$, location $[9,15]$, diagnostic criteria $[9,20,22]$ and study quality $[9,15,20]$.

\section{Methods}

Findings are presented in accord with the PRISMA guidelines; the protocol was pre-registered on PROSPERO (registration number: CRD42017071663).

\section{Search strategy and screening}

A structured search strategy was applied by KH (Online Resource 1). Due to the comprehensiveness of their search, we adapted relevant terms from Rees et al.'s [14] systematic review on the prevalence of mental health disorders in adult ethnic minority populations in England, incorporating incidence terms and iteratively refining the strategy according to our success in identifying relevant papers.

We first searched for previous reviews through to 03.07.17 with no publication date restriction in nine databases: MEDLINE; Embase; PsycINFO; CINAHL; Cochrane Database of Systematic Reviews; Database of Abstracts of Reviews of Effects (DARE); The Campbell Collaboration Online Library; NHS Evidence; and National Institute for Health Research's (NIHR) Journals Library and Policy Research Programme; as well as King's Fund reference lists. In PROSPERO we identified ongoing reviews and contacted authors (the authors of a review [21] forwarded their paper in December 2017). We also conducted backward and forward citation searches (in Google Scholar).

Records were imported into EndNote and Rayyan QCRI software for independent screening by two reviewers $(\mathrm{KH}$ and $\mathrm{EBH}$ ) on title and abstract, and then on full text. Consensus was reached by discussion or, if necessary, by resort to a third reviewer (KB).

After screening reviews, we checked the reference lists of included meta-analytic reviews on the incidence of psychotic disorders $(n=8)[8,9,11,15,19-22]$ to identify relevant primary studies for further assessment of ethnic variations in psychosis risk in England. The most comprehensive search for primary studies covering both nonaffective and affective psychoses specifically in England and by different ethnic groups considered literature only up to 2009 [11], so we also supplemented the primary study literature obtained from previous reviews with an additional search for primary studies from 2010 until the end of 2018 in three databases: MEDLINE; Embase; and PsycINFO, as well as contacted experts in the field to identify recent studies. We combined both the primary studies carried forward from the previous meta-analytic reviews, and those more recently published (2010-2018), into our updated overall meta-analyses.

\section{Inclusion/exclusion criteria}

\section{Study design}

All relevant systematic reviews or meta-analyses were initially included with no restrictions on methods. When 
subsequently checking for primary studies for meta-analyses, we only included those with relevant quantitative data for pooling with no further restrictions on study design (e.g. all relevant observational studies were included, including population-based cohort and cross-sectional studies).

\section{Outcomes}

We included incident cases of diagnosis of psychosis in adult populations only. We defined incidence as " $[t]$ he number of instances of illness commencing, or of persons falling ill [i.e. through first contact with mental health services or first hospital admissions for psychotic disorders], during a given period in a specified population" [28]. As such, incidence is identified through first diagnosis.

In line with others $[11,15,21,23]$, we followed a pragmatic classification of psychosis types due to changing diagnostic categories over time and between studies. We included a wide range and broad classifications of nonaffective psychoses (clinical evaluation or diagnostic criteria such as Diagnostic and Statistical Manual (DSM) or the International Classification of Diseases (ICD), e.g. ICD-10 codes F20-29) and affective psychoses (clinical evaluation or diagnostic criteria such as DSM and ICD, e.g. ICD-10 codes F30-33, albeit with some papers failing to distinguish these from less severe disorders, e.g. ICD-10 codes F34-39, in which case we still included these broader classifications).

\section{Geographical and healthcare setting}

We only included studies wholly or partially conducted in England to ensure a consistent geographical coverage and to explore variations in risk across areas within that geography. We included studies in population-based or non-populationbased settings (e.g. institutional settings such as hospitals).

\section{Language and publication status}

Due to our focus on England, we only included English language papers in peer-reviewed journals or reports published through recognised platforms such as government or university websites, excluding book chapters or conference papers.

\section{Data extraction and quality assessment}

A data extraction form was piloted and iteratively amended to improve relevant data capture. One reviewer extracted data for meta-analyses $(\mathrm{KH})$, checked by another reviewer $(\mathrm{KB})$. When there was significant suspected overlap in samples across papers, we selected the paper with the most comprehensive analysis in terms of the specificity or number of ethnic categories, or if similar ethnic categories were applied we chose relevant data from the largest sample size.

Quality assessments were completed by two independent reviewers ( $\mathrm{KH}$ and $\mathrm{MO}$ or $\mathrm{EBH}$ ) reaching consensus, with differences reconciled by a third reviewer (KB). The AMSTAR checklist was used to assess quality of previous reviews (Online Resource 2). For primary studies included in our refined meta-analyses, we adapted a verified [11, 15] and recently adapted [21] 5-item quality assessment tool and added an item to assess the specificity or clarity of the use of ethnic/national categories in the studies' analyses taken from another verified [29] and replicated [30] tool (Online Resource 3).

\section{Meta-analyses}

We conducted random effects meta-analyses allowing for suspected heterogeneity between effect estimates [31]. Cumulative forest plots by study years were generated in Comprehensive Meta-Analysis 3.3 by KH to inspect ethnic variations in risk over time [32]. We calculated the relative risk (RR) — as used in previous meta-analyses with a similar scope (see Table 1) - to estimate the ratio of the probability of the incidence of receiving a diagnosis either of non-affective or affective psychoses occurring in an ethnic minority group relative to this occurring in the majority reference population in England. We included study reports with sufficient data on numerators/population-at-risk to calculate $\mathrm{RR}$, or extracted estimates directly when authors had not provided the relevant raw data. If available, in such cases, we prioritised the unadjusted estimates as these allow us to make direct population level estimates, were most commonly reported, and because the adjusted estimates were implemented with different standardisations across papers (e.g. age, gender, socioeconomic factors). To investigate heterogeneity, we conducted pre-specified subgroup and sensitivity analyses (see below). We also assessed withingroup heterogeneity by reporting the $I^{2}$-statistic with a $\geq 50 \%$ cut-off for 'substantial heterogeneity' [31] and Cochran's $Q$ with $p$ values $<0.05$ to indicate significant within- and between-group heterogeneity.

Some papers reported data by ethnicity, whereas others by nationality or country of birth. We used definitions of ethnicity as provided by included studies, although it was not always clear what generations were represented due to varied sample inclusion criteria and/or insufficient reporting. For papers reporting country of birth data, we made some judgements on the appropriate reclassification into ethnic categories. So, for the White (British) reference category we included the following descriptions: UK-born [24, 27, 33-39], UK-born Europeans [40], 'persons born in the British Isles, including Eire' (p. 96) [7], England-born [41, 42], remainder of the general population excluding Caribbean 
Table 1 Meta-analyses on ethnicity and the incidence of diagnosed psychoses

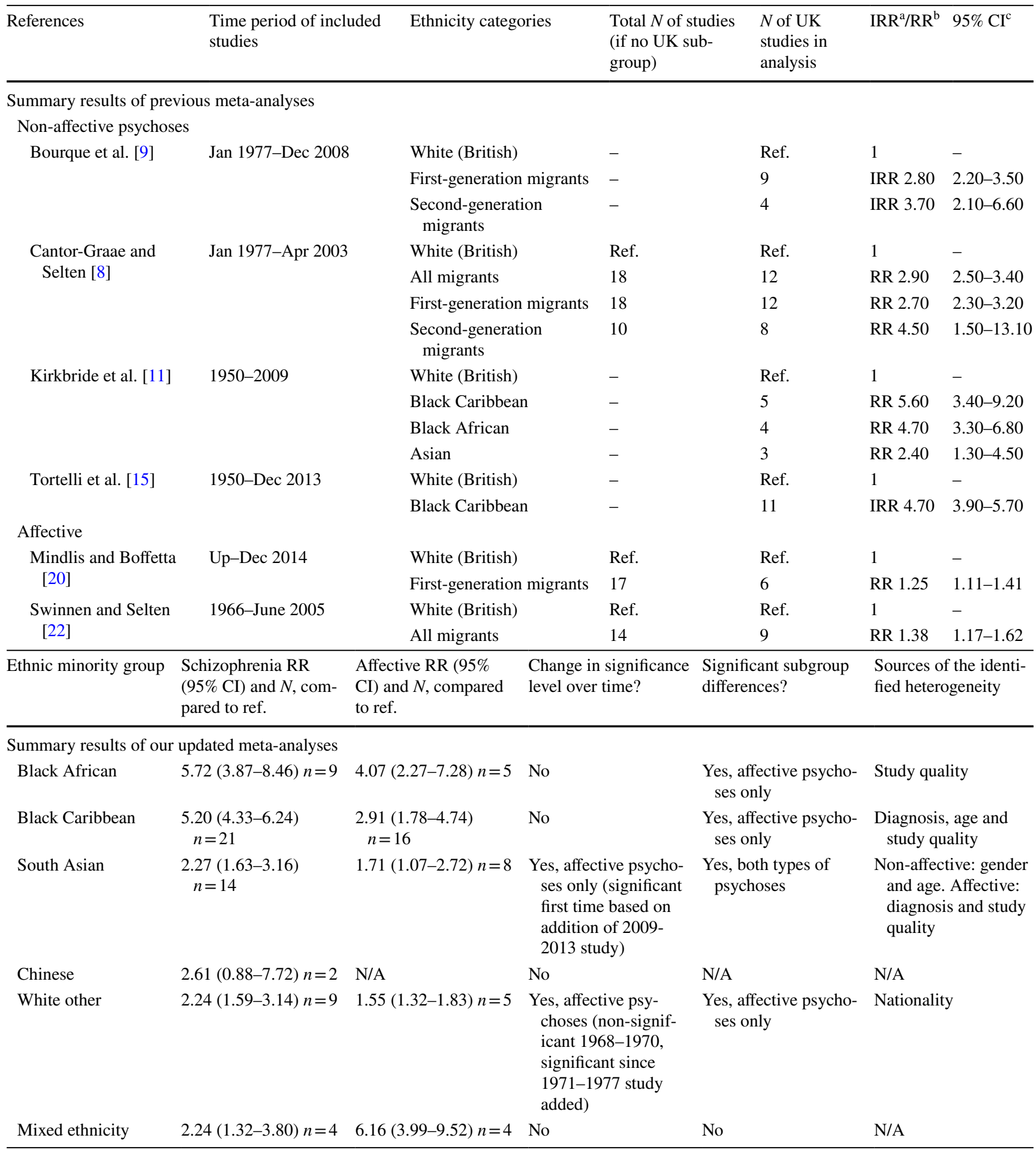

$I R R$ incidence rate ratio, $R R$ relative risk, $C I$ confidence intervals

people [43, 44], White [25, 26, 45-48] and White British [5, 10, 49-53]. For the White Other category we included people born in countries where the majority population is White (e.g. Poland, Ireland, Germany [33, 36-38, 41, 42]). For the Black Caribbean group we included people born in the 'West Indies' [7, 27, 33, 35, 37, 39]. And in the Black African group we included people born in countries in West Africa [39]. However, for this category, we excluded people born in other African countries such as Kenya [42], or New Commonwealth Africa more broadly [36] (i.e. former British 
colonies and dependant territories in Africa that remained in the Commonwealth after independence). This is because these studies include data covering the period from 1976 [36] to 1981 [42] and over this period there was a significant change in this category as a result of immigration from New Commonwealth Africa (including from Kenya) of people with a South Asian ethnic origin, so not Black African [36, 54-56].

As meta-regressions are not recommended with less than ten studies [31] — rendering them impractical across a number of ethnic groups-we favoured subgroup analyses when there were available data for nationality, gender, age (16-29 years vs. $30+$ years as most studies reporting age data employ these ranges), location (combining all estimates from studies in London vs. an aggregated estimate of studies from (smaller) urban areas outside of London due to limited availability of data by specific locations) and broadly defined vs. more specific diagnostic criteria (i.e. non-affective psychoses unspecified vs. only schizophrenia more narrowly defined; affective illnesses unspecified vs. only affective psychoses more narrowly defined (e.g. ICD-10 codes F30-33)). We also conducted sensitivity analyses of lower vs. high quality studies (the latter with a score of 5 or 6 in our quality assessment).

\section{Results}

The flow diagram of searches and screening is found in Online Resource 4 (reasons for exclusions in Online Resource 5). Initially we identified 30 systematic reviews relating to the prevalence and/or incidence of mental illnesses [8, 9, 11, 14, 15, 19-22, 57-77], of which eight metaanalytic reviews provided data by ethnicity on the incidence of diagnosed psychotic illness in adult populations in England $[8,9,11,15,19-22]$. From their reference lists, 24 primary study papers were included $[5,7,10,24-27,33-47$, $49,51]$. These were combined in our overall updated metaanalyses with the four additional primary study papers [48, $50,52,53]$ identified in our electronic searches for more recent studies between 2010 and 2018. No additional studies of relevance were identified from the expert consultation.

The key characteristics of included studies can be found in Online Resource 6 and summary results of previous metaanalyses and our updated meta-analyses in Table 1 (with more detailed statistics in Online Resource 7).

\section{Non-affective psychoses}

Twenty-five papers provided data on non-affective psychoses [5, 7, 10, 26, 33-53]. In Online Resource 7 we report estimates for both non-affective psychoses overall and schizophrenia, while in the cumulative forest plots we report schizophrenia only as most data related to this particular diagnosis.

The highest point estimate of incident diagnosed schizophrenia relative to the reference population was found in the Black African population (RR 5.72, 95\% CI 3.87-8.46, $n=9$ ). The cumulative forest plot (Fig. 1) shows that the risk of schizophrenia diagnosis has been significantly higher for Black African people from 1965 to 2013, although indicates decreasing effect size with time (possibly a result of the especially high risk found in Rwegellera's [39] early study of West African migrants). There was potential for substantial heterogeneity $\left(I^{2}=73.81 \%, Q=30.54, p<0.01\right)$, but no significant differences in subgroup analyses (Online Resource 7).

Figure 2 shows excess risk of incident schizophrenia for the Black Caribbean compared to the reference group (RR $5.20,95 \%$ CI $4.33-6.24, n=21$ ), similar to a recent metaanalysis [15]. The cumulative addition of studies over time in the forest plot illustrates that this finding was sustained between 1961 and 2013, but with potential for substantial heterogeneity $\left(I^{2}=69.42 \%, Q=65.40, p<0.01\right)$. We were unable to detect possible heterogeneity sources (Online Resource 7).

Furthermore, in the South Asian population significantly raised risk relative to the reference population was found (RR 2.27, 95\% CI 1.63-3.16, $n=14$ ). The cumulative forest plot (Sup. Fig. 1, Online Resource 8) shows that, despite the few indications of slightly decreasing risk, the significance of this finding has persisted between 1963 and 2013. However, substantial heterogeneity was a potential factor $\left(I^{2}=84.79 \% ; Q=85.48, p<0.01\right)$. Subgroup analyses (Online Resource 7) showed significantly higher risks in women and for older ( $30+$ years) adults.

We also estimated the average risk of diagnosed schizophrenia in the Chinese population in England (Sup. Fig. 2, Online Resource 8), suggesting an elevated but non-significant risk of schizophrenia compared to the reference population (RR 2.61, 95\% CI 0.88-7.72, $n=2$ ) but no 'substantial heterogeneity' $\left(I^{2}=33.75 \%, Q=1.51, p=0.22\right)$.

Supplementary Figure 3 (Online Resource 8) shows significantly higher risk of diagnosis of schizophrenia for White Other compared to the majority population (RR 2.24, 95\% CI 1.59-3.14, $n=9$ ) between 1963 and 2013. Substantial heterogeneity was suggested $\left(I^{2}=92.39 \% ; Q=105.13\right.$, $p<0.01)$, but subgroup analyses did not identify the possible reasons (Online Resource 7).

Finally, the analysis by people of Mixed Ethnicity also showed a significantly higher risk of incident schizophrenia (RR 2.24, 95\% CI 1.32-3.80, $n=4$ ), with relatively low statistical indications of heterogeneity $\left(I^{2}=18.88 \% ; Q=3.70\right.$, $p=0.30$ ). The cumulative forest plot (Sup. Fig. 4, Online Resource 8) suggests that the estimate has been altered from non-significance to significance over time, although 
Cumulative statistics
Cumulative forest plot

\begin{tabular}{|c|c|c|c|c|}
\hline & & Point & $\begin{array}{c}\text { Lower } \\
\text { limit }\end{array}$ & $\begin{array}{c}\text { Upper } \\
\text { limit }\end{array}$ \\
\hline 1965-1968: Rwegellera 1977 & $24.50,13.00$ to 46.10 & 24.50 & 13.01 & 46.14 \\
\hline 1988-1992: Van Os et al. 1996 & $4.20,2.80$ to 6.20 & 9.96 & 1.77 & 56.09 \\
\hline 1991-1992: King et al. 1994 & $2.59,0.75$ to 8.94 & 6.76 & 1.77 & 25.86 \\
\hline 1996-2000: Kirkbride et al. 2008 & $3.51,2.40$ to 5.12 & 5.74 & 2.43 & 13.54 \\
\hline 1997-1999: Fearon et al. 2006 & $5.80,3.90$ to 8.40 & 5.78 & 3.14 & 10.67 \\
\hline 1997-2002: Mitter et al. 2004 & $7.78,2.38$ to 25.46 & 5.98 & 3.42 & 10.47 \\
\hline 1998-2004: Boydell et al. 2013 & $5.68,3.43$ to 9.43 & 5.92 & 3.72 & 9.44 \\
\hline 2000-2007: Bhavsar et al. 2014 & $5.90,0.87$ to 40.70 & 5.92 & 3.79 & 9.25 \\
\hline 2009-2013: Kirkbride et al 2017 & $4.62,2.64$ to 8.10 & 5.72 & 3.87 & 8.46 \\
\hline & & 5.72 & 3.87 & 8.46 \\
\hline
\end{tabular}

Higher in ref. pop. in England Higher in Black African

Fig. 1 Cumulative forest plot by study year, relative risk (RR) of diagnosed schizophrenia incidence in Black African vs. reference population in England

closer investigation reveals that relative risks may also be dependent on the various classifications of 'Mixed Ethnicity' people. Subgroup analyses revealed no further variations (Online Resource 7).

\section{Affective psychoses}

Seventeen papers provided relevant data for affective psychoses $[5,7,10,24,25,27,33,34,38-40,42,44,47$, 51-53]; most frequently reported as a common typology of disorders.

Figure 3 shows a significantly raised risk of diagnosed affective psychoses for the Black African relative to the reference population (RR 4.07, 95\% CI 2.27-7.28, $n=5$ ). A substantial level of heterogeneity surrounded the result $\left(I^{2}=64.85 \%, Q=11.38, p=0.02\right)$ and indications towards decreasing (although constantly significant) risk between 1965 and 2013. The one lower quality study [39] generated a significantly higher risk than high quality studies (Online Resource 7).

A significantly elevated risk for an incident diagnosis of affective psychoses was found in the Black Caribbean compared to the reference population (RR 2.91, $95 \%$ CI $1.78-4.74, n=16$ ). Figure 4 shows that this result has persisted and remained relatively constant over time (1961-2013). Attention should be paid to evidence of substantial heterogeneity $\left(I^{2}=91.94 \% ; Q=186.07, p<0.01\right)$, which was explained by a range of factors (see Online Resource 7).

The risk of diagnosed affective psychoses was also significantly raised in the South Asian compared to the reference population (RR $1.71,95 \%$ CI $1.07-2.72, n=8$ ), in which time may have been a factor as the previously non-significant estimates in the cumulative forest plot (Sup. Fig. 5, Online Resource 8) changed to significance with the inclusion of a study between 2009 and 2013 [53]. Our $I^{2}$-threshold for 'substantial heterogeneity' was met $\left(I^{2}=70.57 \% ; Q=23.79\right.$, $p<0.01)$. Significantly higher results were found for narrower definitions (of affective psychoses) and high quality studies (Online Resource 7).

A significantly higher average estimate was found for the White Other compared with the reference population for the risk of diagnosed affective psychoses (RR $1.55,95 \%$ CI $1.32-1.83, n=5$, Sup. Fig. 6, Online Resource 8). Substantial heterogeneity was not detected $\left(I^{2}=33.24 \% ; Q=5.99\right.$, $p=0.20$ ). Although the earliest estimate of Eastern European migrants from 1968 to 1970 [38] was non-significant, the estimate for the White Other group has remained significantly 


\begin{tabular}{|c|c|c|c|c|}
\hline Study name & RR \& $95 \% \mathrm{Cl}$ (for individual study) & & dlative ste & \\
\hline & & Point & $\begin{array}{c}\text { Lower } \\
\text { limit }\end{array}$ & $\begin{array}{c}\text { Upper } \\
\text { limit }\end{array}$ \\
\hline 1961: Hemsi 1967 & $3.97,2.10$ to 7.47 & 3.97 & 2.10 & 7.49 \\
\hline 1963-1969: Giggs 1973 & $6.58,4.80$ to 9.03 & 5.53 & 3.45 & 8.85 \\
\hline 1965-1969: Castle et al. 1991 & $5.30,2.60$ to 10.70 & 5.84 & 4.46 & 7.63 \\
\hline 1970-1974: Castle et al. 1991 & $8.20,4.30$ to 13.20 & 6.20 & 4.82 & 7.96 \\
\hline 1975-1979: Castle et al. 1991 & $6.00,3.60$ to 9.60 & 6.18 & 4.99 & 7.65 \\
\hline 1976: Dean et al. 1981 & $5.10,4.20$ to 6.20 & 5.56 & 4.82 & 6.43 \\
\hline 1980-1983: McGovern and Cope 1987 & $6.55,4.67$ to 9.18 & 5.70 & 5.00 & 6.51 \\
\hline 1980-1984: Castle et al. 1991 & $4.00,2.40$ to 6.90 & 5.60 & 4.90 & 6.41 \\
\hline 1981: Cochrane and Bal 1987 & $4.15,3.42$ to 5.02 & 5.30 & 4.52 & 6.21 \\
\hline 1984-1986: Harrison et al. 1988 & $12.66,5.01$ to 32.01 & 5.47 & 4.61 & 6.49 \\
\hline 1984-1987: Thomas et al. 1993 & $3.04,1.60$ to 5.78 & 5.31 & 4.47 & 6.31 \\
\hline 1988-1992: Van Os et al. 1996 & $3.10,2.00$ to 4.70 & 5.08 & 4.26 & 6.06 \\
\hline 1991-1992: King et al. 1994 & $4.87,2.13$ to 11.12 & 5.07 & 4.28 & 6.00 \\
\hline 1991-1993: Bhugra et al. 1997 & $1.92,1.23$ to 3.02 & 4.73 & 3.87 & 5.77 \\
\hline 1992-1994: Harrison et al. 1997 & $10.12,5.24$ to 19.53 & 4.92 & 4.02 & 6.02 \\
\hline 1996-2000: Kirkbride et al. 2008 & $4.17,2.86$ to 6.09 & 4.85 & 4.02 & 5.86 \\
\hline 1997-1999: Fearon et al. 2006 & $9.10,6.60$ to 12.60 & 5.10 & 4.19 & 6.21 \\
\hline 1997-2002: Mitter et al. 2004 & $4.50,1.74$ to 11.65 & 5.08 & 4.19 & 6.15 \\
\hline 1998-2004: Boydell et al. 2013 & $8.09,4.90$ to 13.00 & 5.21 & 4.32 & 6.28 \\
\hline 2000-2007: Bhavsar et al. 2014 & $12.01,1.66$ to 86.77 & 5.24 & 4.35 & 6.32 \\
\hline 2009-2013: Kirkbride et al. 2017 & $3.74,1.39$ to 10.05 & 5.20 & 4.33 & 6.24 \\
\hline & & 5.20 & 4.33 & 6.24 \\
\hline
\end{tabular}

Fig. 2 Cumulative forest plot by study year, relative risk (RR) of diagnosed schizophrenia incidence in Black Caribbean vs. reference population in England

higher than in the reference population from 1971 to 2013. Subgroup analyses showed a significantly higher risk in Irish than in Eastern European people $(p<0.01)$ (Online Resource 7).

The analysis of Mixed Ethnicity people suggested a significantly elevated risk of incident affective psychoses (RR 6.16, 95\% CI 3.99-9.52, $n=4)$, with low statistical indications of heterogeneity $\left(I^{2}=5.13 \% ; Q=3.16, p=0.37\right)$. The cumulative forest plot (Sup. Fig. 7, Online Resource 8) suggests that this estimate has remained significantly higher from 1996 to 2013.

\section{Discussion}

\section{Summary of principal findings}

This systematic review included refined meta-analyses of ethnic variations in risk of diagnosed psychotic illness that uniquely covered both non-affective and affective psychoses, a more complete range of ethnic groups than previously, change over time, and heterogeneity 


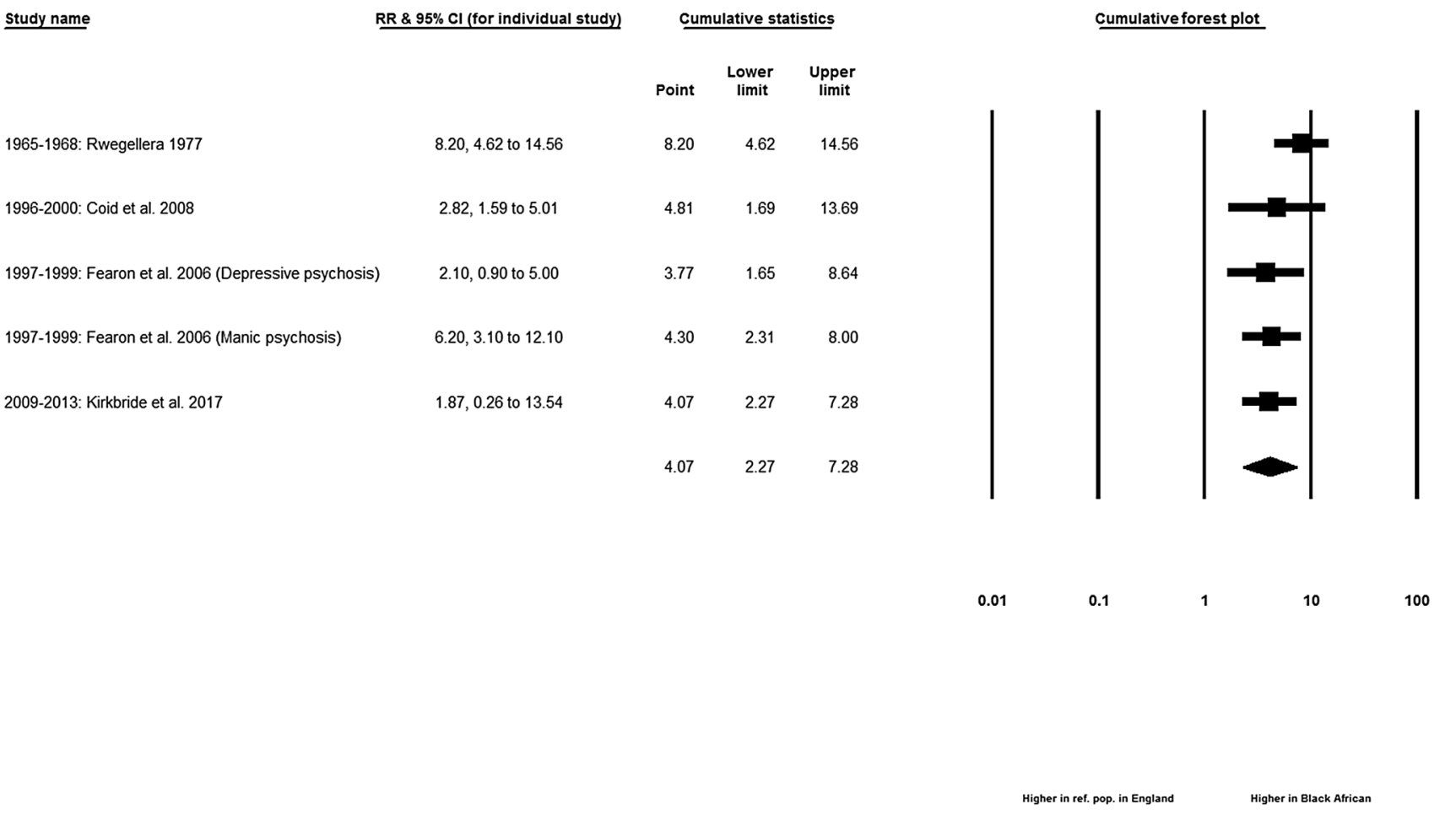

Fig. 3 Cumulative forest plot by study year, relative risk (RR) of incidence of diagnosed affective psychoses in Black African vs. reference population in England

in outcomes across papers and the sources of this. We found excess risks especially of schizophrenia for ethnic minority people. The highest point estimates were found in the Black African and Black Caribbean populations, whereas modestly raised risks were also found in the South Asian, White Other and Mixed Ethnicity populations, respectively, compared to the reference population. Gender and age were relevant in the South Asian analyses. For the respective Black African, South Asian and White Other analyses there were trends, albeit non-significant, towards lower risks over time compared to the reference population.

For affective psychoses, risks were significantly elevated for all ethnic minority groups. Substantial heterogeneity was revealed (apart from in the Mixed Ethnicity analysis). However, caution needs to be used in interpretations due to limited available data for respective analyses.

\section{Comparison with previous meta-analyses}

We confirm previously identified patterns of heightened risk of diagnosed schizophrenia in ethnic minority or migrant populations compared to ethnic majority or 'native' populations, particularly in Black ethnic groups (see Table 1). We also confirm the modestly elevated risk in South Asian people compared to the reference population in England, with a slightly lower but more precise point estimate compared to a similar meta-analysis from 2012 [11]. We provide novel data on the risk of schizophrenia for Mixed Ethnicity and White Other groups (including nationality, i.e. Eastern European and Irish people) and of affective psychoses for all ethnic groups-both cases in which data specific to England or the UK has not previously been pooled.

\section{Strengths and limitations}

Our thorough search strategy ensured a comprehensive mapping of research on the incidence of severe mental illness. Although the refined meta-analyses we conducted emerge from studies referenced in previous meta-analytic reviews, we also uniquely identified more recent primary studies published between 2010 and 2018 through updated searches. A potential limitation is that we included all relevant studies regardless of the study design to enable a sufficient number of effect estimates across ethnic groups to conduct respective analyses. Other authors have used stricter eligibility criteria, including for example only population-based incidence studies [20, 22]. However, we performed sensitivity analyses for study quality, which did not affect the results for non-affective psychoses but across analyses for affective psychoses.

A further caveat is the use of data on first contact with health services or first hospital admissions within a defined 


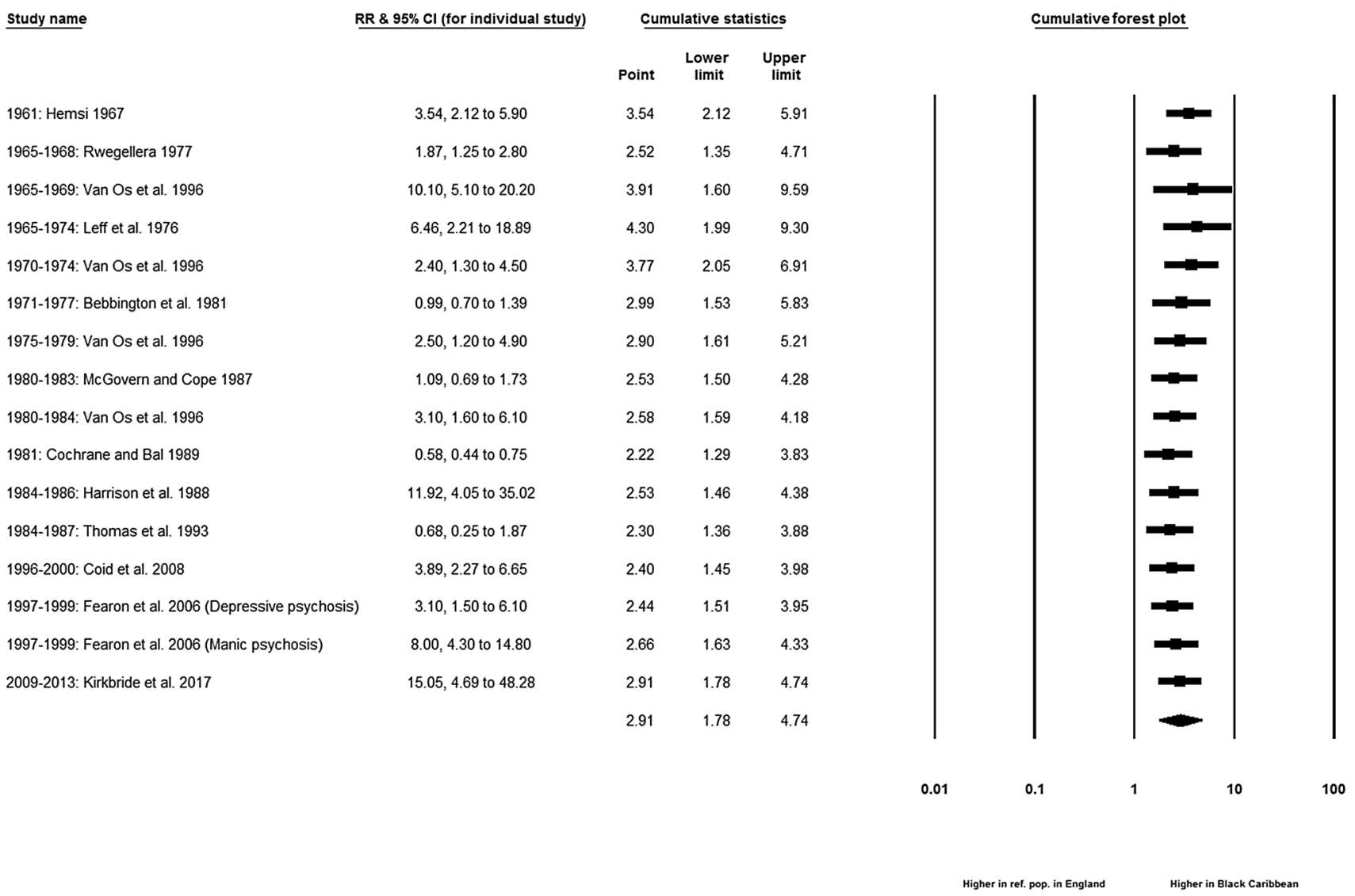

Fig. 4 Cumulative forest plot by study year, relative risk (RR) of incidence of diagnosed affective psychoses in Black Caribbean vs. reference population in England

timeframe as an indicator of the incidence of new diagnoses. This does not cover onsets of illness that do not come into contact with mental health services or hospitals within the given period or differences in duration, severity and relapse, while pathways to care may vary across ethnic groups [78].

A methodological problem in incidence meta-analyses [79] is that larger studies exert more influence on pooled estimates, concealing known variations across sites stemming from different population characteristics. Randomeffects meta-analyses were therefore used to account for population differences, and measures of heterogeneity investigated and reported.

Our study also uniquely aimed to mitigate against bias arising from broad categorisations of ethnic minority and/ or migrant groups. Here we were able to consistently define ethnicity by covering five groupings of ethnic minority people, examine subgroup differences within these groups, and report on the handful of studies that covered Chinese people. However, given the limited number of relevant studies for respective outcomes, we included country of birth data (England) in addition to ethnic data (White or White British) for our reference population to enable a sufficient number of studies across the respective analyses for meaningful pooling. As this meant that the reference group did not exclusively consist of the White British majority, this may have somewhat reduced the size of the observed effects.

\section{Implications for policy and practice}

As most incidence data is based on treated cases, due consideration needs to be afforded to the common pathways to mental health care for ethnic minority groups. Despite research showing that compulsory admission is particularly high for Black ethnic groups [29, 30, 78, 80], compulsory admission rates are not necessarily associated with incidence per se. These admissions are based on the subjective perceptions of authorities, rather than confirmed incidence cases, that the persons in question may be at risk to themselves or others due to mental health concerns. As such, the facilitation of less coercive alternatives in key areas is vital, such as general practitioner and community mental health services, preventing 'emergency' solutions (i.e. compulsory admissions) from remaining the sole option.

Our analyses, with significantly higher risks of diagnosed psychotic disorders across multiple ethnic minority groups over time compared to the reference population, seem to rule 
out the possibility that a single biological or genetic factor is linked to psychosis risk. This lends support to the thesis that the wider social environment influences risks $[8,9,11,15$, 19]. A social environmental explanation we believe deserves attention is the high documented levels of historic and contemporary racial injustice and ethnic discrimination in White majority contexts such as the UK [9, 20, 22, 81, 82]. Experienced discrimination [8] and perceived discrimination [67, $81,82]$ have been shown to contribute to the development of a paranoid attributional style and mental illness [8, 83], including in dose-response analyses in the Netherlands [82] and the UK [84] suggesting a cumulative adverse effect with increasing levels of racial and ethnic discrimination.

Mental health inequalities relating to 'race' have recently re-emerged in the UK policy agenda, as evidenced by the Race Disparity Audit [85] established by the previous Prime Minister and subsequent review of the Mental Health Act [86] that recognised the disparities particularly affecting Black ethnic groups adversely in relation to mental health outcomes and care pathways or treatment. The review of the Mental Health Act [86] also included a separate qualitative exploration of the perspectives of people of African and Caribbean descent, which especially highlighted the issue of racism and discrimination. However, several critical responses to the review [87-89] suggested that although it had proposed solutions, these tended to focus on already-existing practices within the mental health system. The wider determinants of the inequalities the review highlighted-with associated forms of racism that permeate societal structures and their key institutions-were not considered, with the focus instead concentrated on micro-interventions such as 'cultural competency' training for individual practitioners. Despite acknowledging these interventions' potential intrinsic value, this orientation might come at the expense of a broader, more integrated whole systems approach [87-89]. So, it is unclear how wide-reaching the initiative will be. Previous 'race equality' initiatives, for example, have not resulted in adequate public health responses [90], or population-level interventions to tackle these inequalities [81,90].

\section{Implications for research}

This systematic review benefitted from a comprehensive search strategy that also involved topic experts. Only four relevant papers $[48,50,52,53]$ (with one integrating previous datasets [52]) were identified from 2010 until the end of 2018 to update previous meta-analyses on the diagnosed incidence of psychosis by ethnicity in England. The commissioning of more studies would enhance the evidence base and could help future reviewers to build on our work to further improve understanding, particularly of how the range of potential confounding factors (some of which the additional evidence enabled us to investigate) might moderate any observed ethnic inequalities. Future primary studies should ideally provide data by more specific ethnic categories and more frequently report potential explanatory factors for these inequalities. Indeed, few studies provide relevant data by socio-economic status or migrant generation across ethnic groups, let alone experiences of racism and discrimination. Our findings suggest that host societal or post-migratory explanations might be pertinent, with the proportion of people in the second and third generations likely to have increased over time within more established ethnic minority groups in England while inequalities in diagnosed incidence of psychoses have significantly persisted. However, further investigations are required.

The role of place in shaping the higher relative risk for ethnic minority people should also be investigated further. Previous studies suggest a particular importance of larger urban areas or greater urbanicity in explaining risks $[11,13]$, but relative to the reference population we did not find significant differences in risks when comparing studies conducted in London to studies conducted in smaller urban areas in England for any ethnic minority group. We also encourage researchers to compare findings from England with findings pertaining to ethnic minority groups in other contexts.

Acknowledgements The research reported in this paper takes part of the emerging work of the Synergi Collaborative Centre, which is a 5 -year national initiative to build a knowledge hub on ethnic inequalities and multiple disadvantage in severe mental illness in the UK. The Centre has been funded by the Lankelly Chase Foundation. The funder of the study had no role in study design, data collection, data analysis, data interpretation, or writing of the report.

Author contributors $\mathrm{KB}, \mathrm{JN}$ and $\mathrm{KH}$ were involved in the conception and design of the review. $\mathrm{KH}$ designed and conducted the searches. $\mathrm{KH}$ and $\mathrm{EBH}$ screened records for inclusion. $\mathrm{KH}$ extracted relevant data from the primary studies included for meta-analyses, which was checked by $\mathrm{KB}$. KH and $\mathrm{MO}$ or $\mathrm{EBH}$ performed quality assessment, with differences to be reconciled by KB. KH conducted the meta-analyses. $\mathrm{KB}$ and $\mathrm{JN}$ engaged in critically interpreting the analyses, MO in the interpretation of statistical data. $\mathrm{KH}$ drafted the manuscript. KB and JN contributed to commenting on consecutive drafts and suggesting revisions of the manuscript in the context of the wider published literature. All authors reviewed the manuscript and approved the final version. $\mathrm{KB}$ is the $\mathrm{PI}$, corresponding author and guarantor.

\section{Compliance with ethical standards}

Conflict of interest The authors declare that they have no conflict of interest.

Ethical statement As this is a systematic review of previous research, the manuscript does not contain any new patient data.

Open Access This article is distributed under the terms of the Creative Commons Attribution 4.0 International License (http://creativeco mmons.org/licenses/by/4.0/), which permits unrestricted use, distribution, and reproduction in any medium, provided you give appropriate credit to the original author(s) and the source, provide a link to the Creative Commons license, and indicate if changes were made. 


\section{References}

1. Malzberg B (1964) Mental disease among native and foreignborn whites in New York state, 1949-1951. Mental hygiene 48:478-499

2. Werbeloff N, Levine SZ, Rabinowitz J (2012) Elaboration on the association between immigration and schizophrenia: a population-based national study disaggregating annual trends, country of origin and sex over 15 years. Soc Psychiatry Psychiatr Epidemiol 47(2):303-311. https://doi.org/10.1007/s0012 7-011-0342-3

3. Weiser M, Werbeloff N, Vishna T, Yoffe R, Lubin G, Shmushkevitch M, Davidson M (2008) Elaboration on immigration and risk for schizophrenia. Psychol Med 38(8):1113-1119. https:// doi.org/10.1017/S003329170700205X

4. Bruxner G, Burvill P, Fazio S, Febbo S (1997) Aspects of psychiatric admissions of migrants to hospitals in Perth, Western Australia. Aust N Z J Psychiatry 31(4):532-542. https://doi. org/10.3109/00048679709065075

5. Fearon P, Kirkbride JB, Morgan C, Dazzan P, Morgan K, Lloyd T, Hutchinson G, Tarrant J, Fung WL, Holloway J, Mallett R, Harrison G, Leff J, Jones PB, Murray RM (2006) Incidence of schizophrenia and other psychoses in ethnic minority groups: results from the MRC AESOP study. Psychol Med 36(11):15411550. https://doi.org/10.1017/s0033291706008774

6. Ødegård Ø (1932) Emigration and insanity: a study of mental disease among the Norwegian born population of Minnesota. Acta Psychiatrica et Neurologica Scandinavica 4:1-206

7. Hemsi LK (1967) Psychiatric morbidity of West Indian immigrants. Soc Psychiatry 2(3):95-100. https://doi.org/10.1007/ bf00578322

8. Cantor-Graae E, Selten J-P (2005) Schizophrenia and migration: a meta-analysis and review. Am J Psychiatry 162(1):12-24. https://doi.org/10.1176/appi.ajp.162.1.12

9. Bourque F, van der Ven E, Malla A (2011) A meta-analysis of the risk for psychotic disorders among first- and secondgeneration immigrants. Psychol Med 41(5):897-910. https:// doi.org/10.1017/s0033291710001406

10. Coid JW, Kirkbride JB, Barker D, Cowden F, Stamps R, Yang M, Jones PB (2008) Raised incidence rates of all psychoses among migrant groups: findings from the East London first episode psychosis study. Arch Gen Psychiatry 65(11):1250-1258. https://doi.org/10.1001/archpsyc.65.11.1250

11. Kirkbride JB, Errazuriz A, Croudace TJ, Morgan C, Jackson D, Boydell J, Murray RM, Jones PB (2012) Incidence of schizophrenia and other psychoses in England, 1950-2009: a systematic review and meta-analyses. PLoS One. https://doi. org/10.1371/journal.pone.0031660

12. Gottesman II (1991) Schizophrenia genesis: the origins of madness. WH Freeman/Times Books/Henry Holt \& Co, New York

13. Allardyce J, Boydell J, Van Os J, Morrison G, Castle D, Murray RM, McCreadie RG (2001) Comparison of the incidence of schizophrenia in rural Dumfries and Galloway and urban Camberwell. Br J Psychiatry 179:335-339

14. Rees R, Stokes G, Stansfield C, Oliver E, Kneale D, Thomas J (2016) Prevalence of mental health disorders in adult minority ethnic populations in England: a systematic review. University College London Institute of Education EPPI Centre, London

15. Tortelli A, Errazuriz A, Croudace T, Morgan C, Murray RM, Jones PB, Szoke A, Kirkbride JB (2015) Schizophrenia and other psychotic disorders in Caribbean-born migrants and their descendants in England: systematic review and meta-analysis of incidence rates, 1950-2013. Soc Psychiatry Psychiatr Epidemiol 50(7):1039-1055. https://doi.org/10.1007/s00127-015-1021-6
16. Bhugra D, Hilwig M, Hossein B, Marceau H, Neehall J, Leff J, Mallett R, Der G (1996) First-contact incidence rates of schizophrenia in Trinidad and one-year follow-up. Br J Psychiatry 169(5):587-592

17. Hickling FW, Rodgers-Johnson P (1995) The incidence of first contact schizophrenia in Jamaica. Br J Psychiatry 167(2):193-196

18. Mahy GE, Mallett R, Leff J, Bhugra D (1999) First-contact incidence rate of schizophrenia on Barbados. Br J Psychiatry 175:28-33

19. McGrath J, Saha S, Welham J, El Saadi O, MacCauley C, Chant D (2004) A systematic review of the incidence of schizophrenia: the distribution of rates and the influence of sex, urbanicity, migrant status and methodology. BMC Med 2:13-13. https:// doi.org/10.1186/1741-7015-2-13

20. Mindlis I, Boffetta P (2017) Mood disorders in first- and secondgeneration immigrants: systematic review and meta-analysis. Br J Psychiatry 210(3):182-189. https://doi.org/10.1192/bjp. bp. 116.181107

21. Stafford J, Howard R, Kirkbride JB (2017) The incidence of very late-onset psychotic disorders: a systematic review and metaanalysis, 1960-2016. Psychol Med. https://doi.org/10.1017/ s0033291717003452

22. Swinnen SGHA, Selten JP (2007) Mood disorders and migration: Meta-analysis. Br J Psychiatry 190(JAN):6-10. https://doi. org/10.1192/bjp.bp.105.020800

23. Castillejos MC, Martin-Perez C, Moreno-Kustner B (2018) A systematic review and meta-analysis of the incidence of psychotic disorders: the distribution of rates and the influence of gender, urbanicity, immigration and socio-economic level. Psychol Med. https://doi.org/10.1017/s0033291718000235

24. Leff JP, Fischer M, Bertelsen A (1976) A cross-national epidemiological study of mania. Br J Psychiatry 129:428-442

25. Lloyd T, Kennedy N, Fearon P, Kirkbride J, Mallett R, Leff J, Holloway J, Harrison G, Dazzan P, Morgan K, Murray RM, Jones PB (2005) Incidence of bipolar affective disorder in three UK cities: results from the AESOP study. Br J Psychiatry 186:126-131. https://doi.org/10.1192/bjp.186.2.126

26. van Os J, Castle DJ, Takei N, Der G, Murray RM (1996) Psychotic illness in ethnic minorities: clarification from the 1991 census. Psychol Med 26(1):203-208

27. van Os J, Takei N, Castle DJ, Wessely S, Der G, MacDonald AM, Murray RM (1996) The incidence of mania: time trends in relation to gender and ethnicity. Soc Psychiatry Psychiatr Epidemiol 31(3-4):129-136

28. Porta M, Greenland S, Last JM (2008) A dictionary of epidemiology, 5th edn. Oxford University Press, Oxford

29. Bhui K, Stansfeld S, Hull S, Priebe S, Mole F, Feder G (2003) Ethnic variations in pathways to and use of specialist mental health services in the UK. Systematic review. Br J Psychiatry 182:105-116

30. Singh S, Islam Z, Brown L (2013) Ethnicity, detention and early intervention: reducing inequalities and improving outcomes for black and minority ethnic patients: the ENRICH programme, a mixed-methods study. Progr Grants Appl Res 1(3):1-188

31. Higgins JP, Green S (2008) Cochrane handbook for systematic reviews of interventions. Wiley-Blackwell, Chichester

32. Lau J, Schmid CH, Chalmers TC (1995) Cumulative meta-analysis of clinical trials builds evidence for exemplary medical care. J Clin Epidemiol 48(1):45-57. https://doi.org/10.1016/08954356(94)00106-Z

33. Bebbington PE, Hurry J, Tennant C (1981) Psychiatric disorders in selected immigrant groups in Camberwell. Soc Psychiatry 16(1):43-51. https://doi.org/10.1007/bf00578068 
34. Carpenter L, Brockington IF (1980) A study of mental illness in Asians, West Indians and Africans living in Manchester. Br J Psychiatry 137:201-205

35. Castle D, Wessely S, Der G, Murray RM (1991) The incidence of operationally defined schizophrenia in Camberwell, 1965-84. Br J Psychiatry 159:790-794

36. Dean G, Walsh D, Downing H, Shelley E (1981) First admissions of native-born and immigrants to psychiatric Hospitals in South-East England 1976. Br J Psychiatry 139(6):506-512. https://doi.org/10.1192/bjp.139.6.506

37. Giggs J (1973) High rates of schizophrenia among immigrants in Nottingham. Nurs Times 69(38):1210-1212

38. Hitch PJ, Clegg P (1980) Modes of referral of overseas immigrant and native-born first admissions to psychiatric hospital. Soc Sci Med Part A Med Psychol Med Sociol 14(4):369-374. https://doi. org/10.1016/S0271-7123(80)90423-X

39. Rwegellera GGC (1977) Psychiatric morbidity among West Africans and West Indians living in London. Psychol Med 7(2):317329. https://doi.org/10.1017/S0033291700029421

40. Thomas CS, Stone K, Osborn M, Thomas PF, Fisher M (1993) Psychiatric morbidity and compulsory admission among UK-born Europeans, Afro-Caribbeans and Asians in central Manchester. $\mathrm{Br}$ J Psychiatry 163(1):91-99. https://doi.org/10.1192/bjp.163.1.91

41. Cochrane R, Bal SS (1987) Migration and schizophrenia: an examination of five hypotheses. Soc Psychiatry 22(4):181-191. https://doi.org/10.1007/bf00583553

42. Cochrane R, Bal SS (1989) Mental hospital admission rates of immigrants to England: a comparison of 1971 and 1981. Soc Psychiatry Psychiatr Epidemiol 24(1):2-11

43. Harrison G, Glazebrook C, Brewin J, Cantwell R, Dalkin T, Fox R, Jones P, Medley I (1997) Increased incidence of psychotic disorders in migrants from the Caribbean to the United Kingdom. Psychol Med 27(4):799-806

44. Harrison G, Owens D, Holton A, Neilson D, Boot D (1988) A prospective study of severe mental disorder in Afro-Caribbean patients. Psychol Med 18(3):643-657

45. Bhugra D, Leff J, Mallett R, Der G, Corridan B, Rudge S (1997) Incidence and outcome of schizophrenia in whites, African-Caribbeans and Asians in London. Psychol Med 27(4):791-798

46. King M, Coker E, Leavey G, Hoare A, Johnson-Sabine E (1994) Incidence of psychotic illness in London: comparison of ethnic groups. BMJ 309(6962):1115-1119. https://doi.org/10.1136/ bmj.309.6962.1115

47. McGovern D, Cope RV (1987) First psychiatric admission rates of first and second generation Afro Caribbeans. Soc Psychiatry 22(3):139-149. https://doi.org/10.1007/bf00583848

48. Boydell J, Bebbington P, Bhavsar V, Kravariti E, van Os J, Murray RM, Dutta R (2013) Unemployment, ethnicity and psychosis. Acta Psychiatr Scand 127:202-209

49. Mitter PR, Krishnan S, Bell P, Stewart R, Howard RJ (2004) The effect of ethnicity and gender on first-contact rates for schizophrenia-like psychosis in Bangladeshi, Black and White elders in Tower Hamlets, London. Int J Geriatr Psychiatry 19(3):286-290. https://doi.org/10.1002/gps.1084

50. Bhavsar V, Boydell J, Murray R, Power P (2014) Identifying aspects of neighbourhood deprivation associated with increased incidence of schizophrenia. Schizophr Res 156(1):115-121. https ://doi.org/10.1016/j.schres.2014.03.014

51. Kirkbride JB, Barker D, Cowden F, Stamps R, Yang M, Jones PB, Coid JW (2008) Psychoses, ethnicity and socio-economic status. Br J Psychiatry 193(1):18-24. https://doi.org/10.1192/bjp. bp.107.041566

52. Kirkbride J, Coid JW, Morgan C, Fearon P, Dazzan P, Yang M, Lloyd T, Harrison GL, Murray RM, Jones PB (2010) Translating the epidemiology of psychosis into public mental health: evidence, challenges and future prospects. J Public Mental Health $9(2): 4-13$

53. Kirkbride JB, Hameed Y, Ioannidis K, Ankireddypalli G, Crane CM, Nasir M, Kabacs N, Metastasio A, Jenkins O, Espandian A, Spyridi S, Ralevic D, Siddabattuni S, Walden B, Adeoye A, Perez J, Jones PB (2017) Ethnic minority status, age-at-immigration and psychosis risk in rural environments: evidence from the SEPEA study. Schizophr Bull 43(6):1251-1261

54. Hansen R (2002) Globalization, embedded realism, and path dependence: the other immigrants to Europe. Compara Polit Stud 35(3):259-283. https://doi.org/10.1177/0010414002035003001

55. Hatton TJ, Price SW (2005) Migration, migrants, and policy in the United Kingdom. In: Zimmermann KF (ed) European migration: what do we know. Oxford University Press, Oxford, pp 113-172

56. BBC News (2005) Born abroad-Kenya. BBC, Institute for Public Policy Research, Sheffield University Social and Spatial Inequalities Research Group. http://news.bbc.co.uk/1/shared/spl/hi/uk/05/ born_abroad/countries/html/kenya.stm. Accessed 25 Jun 2019

57. Adelman S, Blanchard M, Livingston G, Adelman S, Blanchard M, Livingston G (2009) A systematic review of the prevalence and covariates of dementia or relative cognitive impairment in the older African-Caribbean population in Britain. Int J Geriatr Psychiatry 24(7):657-665. https://doi.org/10.1002/gps.2186

58. Al-Sharifi A, Krynicki CR, Upthegrove R (2015) Self-harm and ethnicity: a systematic review. Int J Soc Psychiatry 61(6):600-612

59. Anderson FM, Hatch SL, Comacchio C, Howard LM (2017) Prevalence and risk of mental disorders in the perinatal period among migrant women: a systematic review and meta-analysis. Arch Womens Ment Health 20(3):449-462. https://doi.org/10.1007/ s00737-017-0723-z

60. Bhui K, McKenzie K, Rasul F (2007) Rates, risk factors and methods of self harm among minority ethnic groups in the UK: a systematic review. BMC Public Health. https://doi. org/10.1186/1471-2458-7-336

61. Bogic M, Njoku A, Priebe S (2015) Long-term mental health of war-refugees: a systematic literature review. BMC Int Health Hum Rights 15(1):29. https://doi.org/10.1186/s12914-015-0064-9

62. Bronstein I, Montgomery P (2011) Psychological distress in refugee children: a systematic review. Clin Child Fam Psychol Rev 14(1):44-56. https://doi.org/10.1007/s10567-010-0081-0

63. Carrà G, Johnson S (2009) Variations in rates of comorbid substance use in psychosis between mental health settings and geographical areas in the UK. Soc Psychiatry Psychiatr Epidemiol 44(6):429-447. https://doi.org/10.1007/s00127-008-0458-2

64. Cooper B (2005) Schizophrenia, social class and immigrant status: the epidemiological evidence. Epidemiologia e Psichiatria Sociale 14(3):137-144

65. Denzel AD, van Esch AYM, Harte JM, Scherder EJA (2016) Ethnic variations in psychotic disorders in the criminal justice system: a systematic review. Aggress Violent Beh 29:20-29. https://doi. org/10.1016/j.avb.2016.05.006

66. Filges T, Montgomery E, Kastrup M, Jørgensen AMK (2015) The impact of detention on the health of asylum seekers: a systematic review. Campbell Syst Rev 13:1-105

67. Fusar-Poli P, Tantardini M, De Simone S, Ramella-Cravaro V, Oliver D, Kingdon J, Kotlicka-Antczak M, Valmaggia L, Lee J, Millan MJ, Galderisi S, Balottin U, Ricca V, McGuire P (2017) Deconstructing vulnerability for psychosis: meta-analysis of environmental risk factors for psychosis in subjects at ultra highrisk. Eur Psychiatry 40:65-75. https://doi.org/10.1016/j.eurps y.2016.09.003

68. Goodman A, Patel V, Leon DA (2008) Child mental health differences amongst ethnic groups in Britain: a systematic review. BMC Public Health 8:258 
69. McGilloway A, Hall RE, Lee T, Bhui KS (2010) A systematic review of personality disorder, race and ethnicity: prevalence, aetiology and treatment. BMC Psychiatry 10:33

70. Robjant K, Hassan R, Katona C (2009) Mental health implications of detaining asylum seekers: systematic review. Br J Psychiatry 194(4):306-312. https://doi.org/10.1192/bjp.bp.108.053223

71. Sigvardsdotter E, Vaez M, Rydholm Hedman AM, Saboonchi F (2016) Prevalence of torture and other warrelated traumatic events in forced migrants: a systematic review. Torture 26(2):41-73

72. Spallek J, Reeske A, Norredam M, Smith Nielsen S, Lehnhardt J, Razum O (2014) Suicide among immigrants in Europe: a systematic literature review. Oxford University Press, Oxford

73. Storm T, Engberg M (2013) The impact of immigration detention on the mental health of torture survivors is poorly documented-a systematic review. Danish Med J 60(11):A4728

74. Voracek M, Loibl LM (2008) Consistency of immigrant and country-of-birth suicide rates: a meta-analysis. Acta Psychiatr Scand 118(4):259-271

75. Fazel M, Wheeler J, Danesh J (2005) Prevalence of serious mental disorder in 7000 refugees resettled in western countries: a systematic review. Lancet 365(9467):1309-1314. https://doi. org/10.1016/S0140-6736(05)61027-6

76. Kalt A, Hossain M, Kiss L, Zimmerman C (2013) Asylum seekers, violence and health: a systematic review of research in highincome host countries. Am J Public Health 103(3):e30-42. https ://doi.org/10.2105/ajph.2012.301136

77. O’Donoghue B, Roche E, Lane A (2016) Neighbourhood level social deprivation and the risk of psychotic disorders: a systematic review. Soc Psychiatry Psychiatr Epidemiol 51(7):941-950. https ://doi.org/10.1007/s00127-016-1233-4

78. Halvorsrud K, Nazroo J, Otis M, Brown Hajdukova E, Bhui K (2018) Ethnic inequalities and pathways to care in psychosis in England: a systematic review and meta-analysis. BMC Med 16(1):223. https://doi.org/10.1186/s12916-018-1201-9

79. Saha S, Chant D, McGrath J (2008) Meta-analyses of the incidence and prevalence of schizophrenia: conceptual and methodological issues. Int J Methods Psychiatr Res 17(1):55-61. https:// doi.org/10.1002/mpr.240

80. Singh SP, Greenwood N, White S, Churchill R (2007) Ethnicity and the Mental Health Act 1983. Br J Psychiatry 191:99-105

81. Nazroo JY (2015) Ethnic inequalities in severe mental disorders: where is the harm? Soc Psychiatry Psychiatr Epidemiol 50(7):1065-1067. https://doi.org/10.1007/s00127-015-1079-1
82. Veling W, Hoek HW, Mackenbach JP (2008) Perceived discrimination and the risk of schizophrenia in ethnic minorities: a casecontrol study. Soc Psychiatry Psychiatr Epidemiol 43(12):953959. https://doi.org/10.1007/s00127-008-0381-6

83. Garety PA, Kuipers E, Fowler D, Freeman D, Bebbington PE (2001) A cognitive model of the positive symptoms of psychosis. Psychol Med 31(2):189-195

84. Wallace S, Nazroo J, Becares L (2016) Cumulative effect of racial discrimination on the mental health of ethnic minorities in the United Kingdom. Am J Public Health 106(7):1294-1300. https:// doi.org/10.2105/ajph.2016.303121

85. Cabinet Office (2017) Race Disparity Audit: summary findings from the ethnicity facts and figures website. https://assets.publi shing.service.gov.uk/government/uploads/system/uploads/attac hment_data/file/686071/Revised_RDA_report_March_2018.pdf. Accessed 6 Apr 2018

86. Department of Health and Social Care (2018) Modernising the Mental Health Act. Final report of the Independent Review of the Mental Health Act 1983. GOV.UK. https://assets.publishing.servi ce.gov.uk/government/uploads/system/uploads/attachment_data/ file/778897/Modernising_the_Mental_Health_Act_-_increasing _choice_rreducing_compulsion.pdf. Accessed 3 Jun 2019

87. Nazroo J (2019) Modernising the Mental Health Act: a missed opportunity to address ethnic inequalities? Mental Health Today. https://www.mentalhealthtoday.co.uk/innovations/modernisin g-the-mental-health-act-a-missed-opportunity-to-address-ethni c-inequalities. Accessed 3 Jun 2019

88. Fernando S (2018) Review of the Mental Health Act fails to put 'race' on its agenda for change, but acknowledges the reality of institutional racism in the mental health system. Race on the Agenda. https://www.rota.org.uk/content/review-mental-healt h-act-fails-put-\%E2\%80\% 98race\%E2\%80\%99-its-agenda-chang e-acknowledges-reality. Accessed 6 Jun 2019

89. Mental Health Today (2018) Interview: Steve Gilbert on the new Mental Health Act and approaches to tackling injustice. Mental Health Today. https://www.mentalhealthtoday.co.uk/blog/in-ourright-mind/interview-steve-gilbert-mental-health-act. Accessed 6 Jun 2019

90. Fitzpatrick R, Kumar S, Nkansa-Dwamena O (2014) Ethnic inequalities in mental health: promoting lasting positive change. Report of findings to Lankelly Chase Foundation, Mind, The Afiya Trust and Centre for Mental Health 